\title{
Der gute Arzt: ratlos
}

Ö konomisches Denken prägt heute die Medizin. Dass die Zeit passé ist, in der Chefärzte ganz oben thronten und ihnen keine Menschenseele - weder Assistent noch Verwalter - dreinreden konnte (und auch die Patienten kaum eine Frage zu stellen wagten), das ist sicher gut. Dass heute jedoch die Administration im klinischen Geschäft das Sagen hat, ist das andere Extrem. Ursache sind die wirtschaftlichen Zwänge, an allen Ecken und Enden im Gesundheitssystem fehlt Geld. Diese Situation hat den Kaufleuten die neue Rolle zugewiesen, die finanziellen Ressourcen zu verteilen.

Diese Zwänge machen uns jedoch nicht nur das Leben schwer, sie bedrohen auch den eigentlichen Auftrag des Arztes. Eines der charakteristischsten Merkmale des Arztseins war immer schon das Vertrauen zwischen ihm und dem Patienten. Merkantile Interessen spielten da nur eine marginale Rolle. Der Arzt bemüht sich, den leidenden Menschen, der sich ihm anvertraut und Heilung ersehnt, zu verstehen sowie die physischen Wurzeln seines Leidens und seiner Ängste zu orten, um mit seiner Zuwendung, mit Medikamenten oder dem Eingriff des chirurgischen Kollegen seine Gesundheit wiederherzustellen.

Doch mittlerweile hat sich so manches drastisch verändert. Der Arzt wird inzwischen von seinem Management und den Krankenkassen nach dem Umsatz beurteilt, den er seiner Klinik beschert, oder den Kosten, die er sparen hilft. Trotzdem muss natürlich die Qualität der medizinischen Versorgung stimmen. Was aus der Qualität wird, wenn an allen Ecken und Enden gespart wird, hat uns die Automobilindustrie gerade vorgemacht. In der Medizin können wir uns Rückrufaktionen aber nicht leisten!

Und wie soll der Arzt seinen Patienten noch als Patienten begreifen können? Die Prämissen zwingen ihm den leidenden Patienten als Konsumenten medizinischer Leistung, als Kunden auf. De jure trifft das zu: Der Patient, der zu seinem Arzt geht, schließt einen Dienstleistungsvertrag, ist also Kunde. Geht es aber an Diagnose und Behandlung, reduziert sich dieser Kunde rasch wieder zum altmodischen Patienten, der seinem Doktor Vertrauen schenken will. Eine medizinische Behandlung ist immer noch etwas anderes als die Reinigung eines Teppichs oder als die Reparatur des Autos.

Das Klinikmanagement kann für diese unglückselige Situation wenig. Es erfüllt nur die Vorgaben von außen. Es ist die Politik, die sich auf der Suche nach einem Ausweg immer Neues einfallen lässt, das meist nur neue bürokratische Hürden gebiert. An das Wohl des Kranken denken Ausschüsse und Ministerialen selten. Dass der so genannte Gemeinsame Bundesausschuss (G-BA), bestehend aus Juristen, medizinischen Funktionären und Kassenvertretern, dem Patienten zwar ein Rederecht einge- räumt hat, jedoch keinerlei Mitbestimmung, ist bezeichnend. Dieser Ausschuss befindet jedoch darüber, welche Therapien dem gesetzlich Versicherten zustehen, und hat gerade eine neue Behörde zur Qualitätsbewertung medizinischer Arbeit etabliert. Diese Behörde wird künftig entscheiden - natürlich motiviert vom politischen Auftrag, kräftig einzusparen -, welche Therapien für welchen Patienten infrage kommen.

Die ärztliche Ethik wird dabei auf der Strecke bleiben. Kein Mensch wird jemals auch nur anzudeuten wagen, dass die Medizin heute schon dabei ist, ihre Hilfe zu rationieren. Man findet gute Gründe, um den Menschen diese Rationierung als Qualitätssicherung zu verkaufen. Dass sich mit rigiden Sparmaßnahmen automatisch auch die Qualität heben lasse, ist das bekannte Trostpflaster der Ökonomen, die ihre Einschnitte der Öffentlichkeit gegenüber rechtfertigen. Die Patienten müssen es glauben. Wenn wir Ärzte jedoch den Ethos unseres Berufs an den Nagel hängen und uns vordringlich an Maximen der Industrie orientieren, wird sich die Medizin in unserem Lande radikal verändern.

Hoffen wir, dass die Politik irgendwann eine Kehrtwende schafft und eine problemorientierte, präventive Gesundheitspolitik realisiert. Wenn die Solidargemeinschaft der gesetzlichen Krankenversicherung (GKV) nicht mehr bezahlen kann, was medizinisch für alle unverzichtbar ist, muss sich der Staat überlegen, wie durchaus vorhandene wirtschaftliche Ressourcen aus anderen, weniger relevanten Bereichen der Gesellschaft umgeschichtet werden. Denn: Die Gesundheit ist unser höchstes Gut, und der „gute“ Arzt ist verpflichtet, alles dafür zu tun, was die Medizin in ihrem Arsenal bereithält.

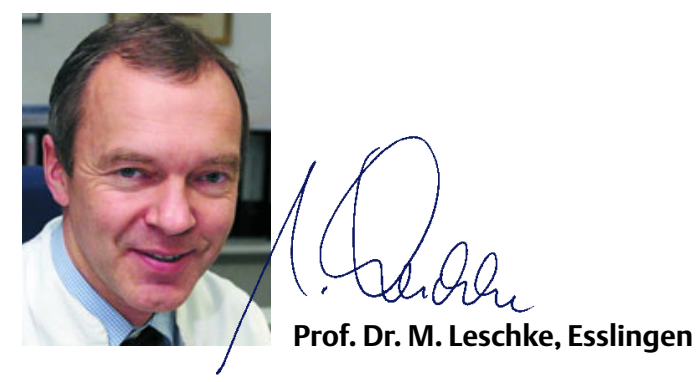

